\title{
A ESTRUTURA DE CUSTOS DAS ACTIVIDADES ECONÓMICAS PORTUGUESAS E O CUSTEIO BASEADO NAS ACTIVIDADES
}

\author{
Conceição Gomes* \\ Lúcia Lima Rodrigues
}

Nos últimos anos, temos verificado uma alteração na estrutura de custos das empresas. Os gastos gerais de fabrico aumentam em detrimento da mão-de-obra directa. Contudo, a componente com maior peso é a dos materiais directos.

O CBA (custeio baseado nas actividades) é um método de custeio que se baseia nas actividades para efectuar a distribuição dos custos indirectos pelos produtos. É um método que está dependente da estrutura de custos, ou seja, segundo a Regra de "Willie Sutton" e o estudo de Vokurka e Lummus (2001), uma empresa com altos gastos gerais é propensa à aplicação do CBA.

Ao analisarmos a estrutura de custos das diversas actividades económicas portuguesas, verificámos que existem actividades aptas $\grave{a}$ implementação do CBA no sector dos serviços bem como na indústria e no comércio. Contudo, apesar desta potencialidade, muitas empresas não optam pelo CBA.

Deste modo, concluimos que a estrutura de custos não é um factor premente à implementação do CBA, existindo outros factores a ter em consideração.

Palavras-chave: custeio baseado nas actividades, contabilidade de gestão, estrutura de custos, gastos gerais de fabrico, sectores de actividade.

\footnotetext{
* Escola Superior de Ciências e Tecnologia - Pólo da Figueira da Foz - Universidade Católica Portuguesa

** Escola de Economia e Gestão - Universidade do Minho
} 


\section{INTRODUÇÃO}

Nos últimos anos, temos verificado uma alteração na estrutura de custos das empresas. A componente que tem um peso significativo é o custo dos materiais, no que diz respeito ao sector da indústria. O custo de mão-de-obra directa é o que tem uma percentagem menor. Todavia, as bases de imputação mais utilizadas são as que estão relacionadas com a mão-de-obra directa.

O CBA (custeio baseado nas actividades) é um método de custeio que se baseia nas actividades para efectuar a distribuição dos custos indirectos pelos produtos. Diferencia-se, essencialmente, do custeio tradicional na forma como trata os gastos gerais que não variam proporcionalmente com o volume de produção. Teve a sua origem no sector industrial, mas hoje em dia já é utilizado pelo sector de serviços e pelas entidades públicas (King et al., 1994; Atkinson et al., 2001).

Através da revisão da literatura, verificou-se que o CBA não se aplica a todas as empresas. Por exemplo, nos sectores onde a maior parte dos seus custos são directos, o custeio tradicional consegue calcular facilmente o custo dos seus produtos. Assim, não se justifica a implementação do CBA, pois numa análise de custo-benefício o custo seria sem dúvida mais alto que o benefício.

Neste estudo, pretendemos, através duma análise da estrutura de custos das diversas actividades económicas pertencentes ao sector da indústria, serviços e do comércio, identificar quais as que são propensas à implementação do CBA.

Deste modo, iremos basear-nos na "Willie Sutton rule" que refere que o CBA deverá ser aplicado nas empresas com grandes gastos gerais de fabrico, principalmente, quando estes têm tendência a crescer e no estudo de Vokurka e Lummus (2001).

\section{ESTRUTURA DE CUSTOS}

A estrutura de custos das diversas empresas tem sofrido diversas alterações. É, usual, encontrarmos na literatura que os custos de mão-deobra directa estão a diminuir implicando um aumento nos gastos gerais de fabrico, o que torna problemático o apuramento do custo dos produtos. Contudo, ao elaborarmos um estudo verificámos que existem vários aspectos a ter em conta.

Segundo Sandretto (1985), é conveniente analisar a estrutura de custos, pois os custos que têm maior percentagem são os que devem ter 
maior controlo. Com a evolução, dos nossos dias, tudo indica que deveriam ser os gastos gerais de fabrico.

Naraynan e Sarkar (1999) referem que, na empresa onde realizaram um estudo sobre o CBA, a maioria dos produtos tinha como custo principal de produção as matérias primas, cerca de $70 \%$ do custo de produção.

Shim e Larkin (1994) verificaram, no estudo que realizaram às empresas industriais americanas, a seguinte estrutura de custos de produção: Materiais directos com 47\%, Mão-de-obra directa com 15\% e Gastos gerais de fabrico com $38 \%$.

A estrutura de custos é um factor a ter em conta na selecção do sistema de custeio a utilizar. Autores como Clarke (1997) dão como exemplo o facto do CBA estar mais relacionado com empresas em que na sua estrutura de custos os gastos gerais possuem uma percentagem elevada. No estudo realizado a grandes empresas industriais na Irlanda, verificou o seguinte em termos de estrutura de custos.

\section{Quadro 1}

Estrutura de custos das empresas na Irlanda

\begin{tabular}{|l|l|}
\hline Mão-de-obra directa & $15 \%$ \\
\hline Materiais directos & $50 \%$ \\
\hline Gastos gerais de fabrico & $18 \%$ \\
\hline Custos indirectos não industriais & $17 \%$ \\
\hline
\end{tabular}

Fonte: Clarke (1997)

A componente de maior peso é os materiais directos. Também, considerou que os custos indirectos não industriais são mais importantes que a mão-de-obra directa em termos de custos de estrutura.

Para Drury (1999), a estrutura de custos está em constante mutação. Os gastos gerais estão a aumentar e os custos de mão-de-obra estão a diminuir a sua importância. Refere que diferentes pesquisas reportam resultados similares em termos de estrutura de custos. A mão-de-obra directa em termos médios varia entre os $10 \%$ até aos $15 \%$ do total dos custos de produção. Também, contradiz o facto dos gastos gerais de fabrico serem o factor dominante dos custos de produção. Drury (1999) concluiu que os materiais directos são os custos predominantes na maioria das indústrias.

Hendricks (1989) analisou a estrutura de custos na indústria, segundo várias actividades económicas. 


\section{Quadro 2}

Estrutura de custos nas várias indústrias nos Estados Unidos da América

\begin{tabular}{|l|l|l|l|}
\hline Indústria & $\begin{array}{l}\text { Materiais } \\
\text { directos }\end{array}$ & $\begin{array}{l}\text { Mão-de-obra } \\
\text { directa }\end{array}$ & $\begin{array}{l}\text { Gastos gerais } \\
\text { de fabrico }\end{array}$ \\
\hline Aeronaves & $51,7 \%$ & $19,3 \%$ & $29 \%$ \\
\hline Computadores & $69,9 \%$ & $7,5 \%$ & $22,5 \%$ \\
\hline Componentes electrónicas & $48,6 \%$ & $15,1 \%$ & $36,3 \%$ \\
\hline Máquinas e tractores & $46 \%$ & $12,8 \%$ & $41,2 \%$ \\
\hline Produtos metálicos & $52 \%$ & $15,7 \%$ & $32,3 \%$ \\
\hline $\begin{array}{l}\text { Componentes e motores } \\
\text { para veículos automóveis }\end{array}$ & $63,8 \%$ & $7,8 \%$ & $28,4 \%$ \\
\hline Material fotográfico & $52,3 \%$ & $11,3 \%$ & $36,5 \%$ \\
\hline
\end{tabular}

Fonte: Hendricks (1989)

Observando este quadro, verificamos que os materiais directos é que têm maior percentagem em todas as indústrias, sendo a mão-de-obra directa a componente menor.

Em Portugal, Alves (2002), também, elaborou um estudo às empresas industriais onde observou a seguinte estrutura de custos.

\section{Quadro 3}

Estrutura de custos em percentagem por actividade económica da indústria transformadora

\begin{tabular}{|l|l|l|l|l|}
\hline & $\begin{array}{l}\text { Mão-de- } \\
\text { obra } \\
\text { directa }\end{array}$ & $\begin{array}{l}\text { Consumo } \\
\text { de } \\
\text { matérias }\end{array}$ & $\begin{array}{l}\text { Gastos } \\
\text { gerais de } \\
\text { fabrico }\end{array}$ & $\begin{array}{l}\text { Outros } \\
\text { gastos } \\
\text { gerais }\end{array}$ \\
\hline $\begin{array}{l}\text { 15 Indústrias alimentares e das } \\
\text { bebidas }\end{array}$ & 7 & 67 & 11 & 16 \\
\hline 17 Fabricação de têxteis & 23 & 40 & 24 & 13 \\
\hline 18-Indústria do vestuário & 15 & 62 & 19 & 6 \\
\hline $\begin{array}{l}\text { 20- Indústria da madeira e da } \\
\text { cortiça }\end{array}$ & 17 & 64 & 13 & 6 \\
\hline $\begin{array}{l}\text { 21- Fabricação da pasta de } \\
\text { papel e cartão }\end{array}$ & 9 & 61 & 13 & 15 \\
\hline $\begin{array}{l}\text { 22-Edição, impressão e } \\
\text { reprodução de suportes de } \\
\text { informação }\end{array}$ & 17 & 43 & 20 & 18 \\
\hline $\begin{array}{l}\text { 24 - Fabricação de produtos } \\
\text { químicos }\end{array}$ & 10 & 64 & 8 & 18 \\
\hline $\begin{array}{l}\text { 25- Fabricação de artigos de } \\
\text { borracha }\end{array}$ & 20 & 50 & 18 & 13 \\
\hline $\begin{array}{l}\text { 26-Fabricação de outros } \\
\text { produtos minerais não } \\
\text { metálicos }\end{array}$ & 22 & 33 & 29 & 16 \\
\hline
\end{tabular}




\begin{tabular}{|l|l|l|l|l|}
\hline $\begin{array}{l}28-\text { Fabricação de produtos } \\
\text { metálicos }\end{array}$ & 27 & 49 & 14 & 9 \\
\hline $\begin{array}{l}29-\text { Fabricação de máquina e } \\
\text { equipamentos }\end{array}$ & 15 & 62 & 11 & 13 \\
\hline $\begin{array}{l}31-\text { Fabricação de máquinas e } \\
\text { aparelhos eléctricos. }\end{array}$ & 7 & 62 & 24 & 8 \\
\hline $34-$ Fabricação de automóveis & 9 & 63 & 21 & 7 \\
\hline $\begin{array}{l}35 \text { - Fabricação de outro } \\
\text { material de transporte }\end{array}$ & 40 & 40 & 20 & 0 \\
\hline $\begin{array}{l}36-\text { Fabricação de mobiliário } \\
\text { e outros }\end{array}$ & 21 & 55 & 12 & 13 \\
\hline
\end{tabular}

Fonte: Alves (2002)

Após toda esta revisão de literatura acerca da estrutura de custos que assenta no sector da indústria, verificámos que uma das componentes que deveria ter mais atenção era a rubrica materiais directos. Sem dúvida, é uma das maiores componentes da estrutura de custos de produção nas actividades económicas do sector da indústria.

\section{A ESTRUTURA DE CUSTOS E AS BASES DE IMPUTAÇÃO}

\section{UTILIZADAS}

O conhecimento da estrutura de custos é muito importante na fase da selecção das bases de imputação para a afectação dos custos indirectos.

Clarke (1997) analisou as bases de imputação utilizadas, nas empresas da Irlanda.

\section{Quadro 4}

Bases de imputação utilizadas nas empresas da Irlanda

\begin{tabular}{|l|l|}
\hline Horas de mão-de-obra directa & $39 \%$ \\
\hline Custo de mão-de-obra directa & $13 \%$ \\
\hline Horas máquina & $22 \%$ \\
\hline Custo de materiais & $7 \%$ \\
\hline Unidades produzidas & $28 \%$ \\
\hline Outros & $22 \%$ \\
\hline
\end{tabular}

Fonte: Clarke (1997) 
Verificou que as horas de mão-de-obra directa continuam a ser as mais utilizadas, apesar da mão-de-obra directa ter o menor peso na estrutura de custos. A sua grande preocupação dirigiu-se para a pequena percentagem dos custos de materiais dado que os custos como a recepção, inspecção e armazenagem das matérias-primas estão a ser afectadas com base nas horas homem, o que leva a algumas distorções em termos de custos dos produtos.

Shim e Larkin (1994), no seu estudo, verificaram nas bases de imputação simples, que a maior percentagem pertence aos custos de mãode-obra directa.

\section{Quadro 5}

Bases de imputação utilizadas nas empresas dos Estados Unidos da América

\begin{tabular}{|l|l|l|}
\hline Base de imputação simples & Horas de mão-de-obra directa & $12,1 \%$ \\
\hline & Custo da mão-de-obra directa & $18,4 \%$ \\
\hline & Horas máquina & $0,7 \%$ \\
\hline & $\begin{array}{l}\text { Número unidades } \\
\text { produzidas }\end{array}$ & $0,7 \%$ \\
\hline Base de imputação múltipla & $\begin{array}{l}\text { Uaterial consumido base de imputação para } \\
\text { cada centro de custo }\end{array}$ & $16,3 \%$ \\
\hline & $\begin{array}{l}\text { Uma base de imputação para } \\
\text { grupos de centros de custos }\end{array}$ & $28,96 \%$ \\
\hline Baseado nas actividades & Baseada nas actividades & $22 \%$ \\
\hline
\end{tabular}

Fonte: Shim e Larkin (1994)

Hendricks (1989) refere que a sua pesquisa conclui que as bases de imputação mais utilizadas são as horas de mão-de-obra padrão seguidas pelos custos de mão-de-obra directa padrão.

\section{Quadro 6}

Bases de imputação utilizadas nos Estados Unidos

\begin{tabular}{|l|l|}
\hline Horas de mão-de-obra directa actuais & $26 \%$ \\
\hline Horas de mão-de-obra directa padrão & $35 \%$ \\
\hline Custos de mão-de-obra directa actuais & $20 \%$ \\
\hline Custos de mão-de-obra directa padrão & $34 \%$ \\
\hline
\end{tabular}




\begin{tabular}{|l|l|}
\hline Horas máquina actuais & $14 \%$ \\
\hline Horas máquina padrão & $34 \%$ \\
\hline Tempo no centro máquina & $7 \%$ \\
\hline Materiais directos & $26 \%$ \\
\hline Unidades de produção & $18 \%$ \\
\hline
\end{tabular}

Fonte: Hendricks (1989)

Nicholls (1992) realizou um estudo no Reino Unido onde verificou que $55 \%$ das empresas que responderam ao inquérito ainda utilizam como base de imputação as horas de mão-de-obra directa.

Em Portugal, na indústria transformadora "as horas de mão-de-obra directa representam a base de imputação mais utilizada nas empresas do sector têxtil, do vestuário, na fabricação de produtos metálicos, de máquinas e aparelhos eléctricos e, ainda, na fabricação de outro material de transporte. Por seu lado, o valor da mão-de-obra directa representa a base de imputação mais utilizada apenas no caso da fabricação de artigos de borracha e matérias plásticas. Em contrapartida, as horas máquina representam a base de imputação mais utilizada em cinco sectores diferentes. E o custo das matérias consumidas representa a base de imputação mais utilizada na indústria alimentar, no vestuário, na fabricação de artigos de borracha e matérias plásticas e na fabricação de máquinas e equipamentos. Por último, as quantidades produzidas representam a base de imputação mais utilizada na indústria editorial, na fabricação de produtos químicos, de outros produtos minerais não metálicos, e de automóveis." (Alves, 2002: 199)

Em suma, verificamos que as empresas ainda não estão a modificar o seu sistema de custeio. Ou seja, apesar da estrutura de custos estar a modificar-se e o custo de mão-de-obra ser a menor componente, ainda, estão a utilizar as horas de mão-de-obra e o custo de mão-de-obra para afectar os custos indirectos. Assusta um pouco constatarmos que os custos indirectos relacionados com as matérias-primas estão a ser distribuídos com base na mão-de-obra.

No caso português, Alves (2002) detectou que o custo do consumo de matérias é a maior componente do custo de produção, excepto na fabricação de outro material de transporte em que o custo de mão-de-obra directa tem o mesmo peso. Comparando a mão-de-obra directa com os gastos gerais de fabrico verificamos que apenas na indústria da madeira e da cortiça, fabricação de produtos químicos, fabricação de artigos de borracha, fabricação de produtos metálicos, fabricação de máquinas e equipamentos, fabricação de outro material de transporte e fabricação de 
mobiliário e outros é que o custo de mão-de-obra directa é superior aos gastos gerais de fabrico.

Apesar de em alguns sectores existirem outras bases que são as mais utilizadas, as horas de mão-de-obra ainda têm um papel fulcral nalgumas actividades o qual não consegue ser justificado pela estrutura de custos.

\section{CARACTERIZAÇÃO DO CBA}

O CBA é um método de custeio que é utilizado na distribuição de custos. O CBA caracteriza-se pela acumulação dos custos nas actividades de uma organização seguindo-se a aplicação desses custos aos produtos/serviços, através dos indutores de custo. (Horngren et al., 2000; Maher et al., 1997)

O CBA difere do custeio tradicional na forma como trata os gastos gerais que não estão relacionados com o volume de produção, e, tem grande aplicabilidade nalgumas empresas. (Innes e Mitchell, 1989)

O CBA "identifica e classifica as actividades dum sistema produtivo em quatro categorias: nível unidade, nível lote, nível manutenção do produto (product-sustaining) e nível manutenção da empresa (facilitysustaining). Os custos das três primeiras categorias de actividades são distribuídos aos produtos usando os indutores de custos que captam o comportamento dos custos que estão a ser distribuídos. Os custos do nível de manutenção da empresa são tratados como custos do período ou são distribuídos ao produto de maneira arbitrária." (Cooper, 1990: 7)

Segundo Christensen e Sharp (1993), Innes et al. (2000), Vokurka e Lummus (2001) e Cotton et al. (2003), o CBA vem associado a diversas áreas disponibilizando informação para determinadas decisões estratégicas: fixação de preços, análise da rendibilidade dos clientes e dos produtos, melhorias dos processos, gestão e redução dos custos e medidas de desempenho das actividades. Cada vez mais as empresas utilizam o CBA para atingir vários objectivos.

Glad (1993) refere que é necessário um período de transição para que os sistemas de contabilidade sejam reestruturados. Após vários estudos verificou que $85 \%$ a $90 \%$ dos custos são de fácil relacionamento com as actividades. A distribuição dos restantes custos é uma tarefa morosa.

Innes e Mitchell (1989) dizem que é conveniente estudar o tipo de organizações que terão benefícios com o CBA. Existem muitos estudos empíricos na indústria, mas deveria ser estudada a aplicabilidade nos serviços no comércio e no sector público. 


\section{A ESTRUTURA DE CUSTOS E O CBA}

Cooper e Kaplan (1998) estabelecem duas regras que definem em que tipo de empresas é que o CBA terá mais impacte, por outras palavras, quando é que as empresas terão benefícios na sua implementação.

A "Willie Sutton rule" define que devemos aplicar o CBA nas áreas com grandes gastos gerais indirectos e com muitos recursos de manutenção, principalmente, quando estas despesas têm tendência a crescer. Quando todos os custos são referentes a materiais directos e mãode-obra directa, quer dizer que estão relacionados directamente com os produtos, o CBA é desprezível, pois o custeio tradicional é suficiente. Se todas as actividades forem do tipo unidade os dois sistemas de custeio dão respostas equivalentes.

Por outro lado, a "high-diversity rule" define que o CBA é útil quando uma exista grande diversidade de produtos, clientes e processos.

A "Willie Sutton rule" está relacionada com a estrutura de custos na medida que relaciona o peso dos gastos gerais de fabrico com o CBA. Com base nesta regra, Vokurka e Lummus (2001) realizaram um estudo de modo a descobrirem qual o nível de gastos gerais de fabrico que uma empresa deve possuir, para que seja propensa a aplicar o CBA. No fundo, o objectivo principal deste estudo foi a determinação de qual o nível em que não se justifica o uso do CBA devido aos seus custos de implementação. Estabeleceram cenários hipotéticos de quatro empresas (W, X , Y e Z) idênticas com cinco produtos ( $\mathrm{A}, \mathrm{B}, \mathrm{C}, \mathrm{D}$ e $\mathrm{E})$. A única diferença entre as empresas era a proporção dos gastos gerais de fabrico. Os produtos eram iguais para todas as empresas, bem como o seu volume. Os produtos entre si variavam na sua complexidade. A era o mais simples e E o mais complexo.

Neste estudo, concluíram que "com GGF à volta dos $15 \%$ ou mais em relação ao custo total, parece que o CBA seria benéfico. Para níveis inferiores a $15 \%$ uma análise custo benefício seria apropriada para investigar com maior profundidade os benefícios da implementação nessa situação específica." (Vokurka e Lummus, 2001: 47)

Considerações importantes serão a complexidade das linhas de produção e operações, o tamanho da empresa e o tempo de espera para implementar o CBA.

Como conclusão "sugerem que mesmo a baixos níveis de gastos gerais de fabrico a diferença entre o custeio tradicional e o CBA poderá ser significativa. As empresas deverão examinar os seus niveis de gastos gerais de fabrico e determinar se o CBA será valioso ou não. Se a empresa tem elevados níveis de gastos gerais de fabrico deverá considerar utilizar o CBA na sua contabilidade de custos. Mesmo a um baixo nível de gastos gerais, uma empresa com um mix vasto de produto se tiver 
actividades identificáveis deverá beneficiar do CBA. Empresas com baixos níveis de gastos gerais de fabrico e um mix estático de produtos poderão achar que o custo de implementação do CBA excede os seus benefícios" (Vokurka e Lummus, 2001: 48).

Bjonernak (1997) considerou a estrutura de custos como uma variável que influencia a implementação do CBA. Nesta variável estudaram a percentagem dos gastos gerais em relação ao valor dos custos adicionados na empresa em vez de ser em relação aos custos totais. Optaram por esta alternativa visto que os materiais directos são uma componente de peso elevado na estrutura de custos e se esta fosse considerada poderia levar a uma distorção dos resultados. No seu estudo, Bjonernak (1997) concluiu que as empresas que apresentam uma alta percentagem de gastos gerais são as primeiras a utilizar o CBA. Afirma que as empresas utilizadoras de CBA têm uma estrutura de custos diferente das não utilizadoras.

As empresas deverão analisar o seu nível de gastos gerais de fabrico para determinar se o CBA será benéfico ou não. Logo, podemos generalizar esta informação para os sectores. Normalmente, as empresas da mesma actividade têm a mesma estrutura de custos. Deste modo, analisaremos a estrutura de custos de diversas actividades económicas de forma a detectar onde será mais vantajoso a implementação do CBA.

\section{OBTENÇÃO, TRATAMENTO DOS DADOS E CARACTERIZAÇÃO DA}

\section{AMOSTRA}

No último estudo realizado tivemos acesso algumas bases de dados em que devido a diversas limitações acabámos por optar pelas estatísticas das empresas do Instituto Nacional de Estatística (INE). As empresas encontravam-se classificadas segundo a Classificação de Actividades de Empresas (CAE Rev. 2.1) com a nomenclatura de três algarismos.

A informação acerca da estrutura de custos das várias actividades económicas foi obtida através das contas de custos da Demonstração de Resultados por natureza que diziam respeito ao ano de 2000. A estrutura de custos resumia-se no seguinte: custo das mercadorias vendidas e matérias consumidas, fornecimentos e serviços externos, custos com pessoal e outros custos e perdas que englobam os restantes custos.

Esta informação foi limitativa ao estudo na medida que a utilização de três dígitos implicou que os sectores tivessem demasiados agregados, ou seja actividades económicas de naturezas diferentes estavam agregadas, bem como na estrutura de custos fornecida estavam alguns custos agregados.

Então, depois de solicitada à Central de Balanços do Banco de Portugal a informação pretendida, foi-nos cedido o mais aproximado. 
Esta entidade cedeu a informação dos custos e perdas por empresa, ocultando a sua identidade, mas classificou-as segundo a Classificação de Actividades de Empresas (CAE Rev. 2.1) a cinco dígitos.

A informação obtida diz respeito a 14199 empresas situadas em Portugal e ao ano de 2002. Em termos de classificações das actividades económicas, não utilizamos todas as secções por não existir informação disponível. As analisadas são: Secção A - Agricultura, Produção animal, caça e silvicultura; Secção B - Pesca; Seç̧ão C - Indústrias extractivas; Secção D - Indústrias transformadoras; Seç̧ão E - Produção e distribuição de electricidade, de gás e água; Secção F - Construção; Secção G - Comércio por grosso e a retalho, reparação de veículos automóveis, motociclos e de bens de uso pessoal e doméstico; Seç̧ão H Alojamento e restauração; Secção I - Transportes, armazenagem e comunicações; Secção K - Actividades imobiliárias, alugueres e serviços prestados às empresas; Secção M - Educação; Secção N - Saúde e Acção social; Secção O - Outras actividades e serviços colectivos, sociais e pessoais.

As empresas encontram-se distribuídas no quadro seguinte.

\section{Quadro 7}

Número de empresas por sector de actividade

\begin{tabular}{|l|l|}
\hline Seç̧ão A - Agricultura, Produção animal, caça e silvicultura & 414 \\
\hline Secção B - Pesca; & 36 \\
\hline Secção C - Indústrias extractivas & 147 \\
\hline Secção D - Indústrias transformadoras & 4980 \\
\hline Secção E - Produção e distribuição de electricidade, de gás e água & 91 \\
\hline Seç̧ão F - Construção & 1582 \\
\hline $\begin{array}{l}\text { Secção G - Comércio por grosso e a retalho, reparação de veículos } \\
\text { automóveis, motociclos e de bens de uso pessoal e doméstico }\end{array}$ & 4300 \\
\hline Secção H - Alojamento e restauração & 260 \\
\hline Secção I - Transportes, armazenagem e comunicações & 954 \\
\hline $\begin{array}{l}\text { Secção K - Actividades imobiliárias, alugueres e serviços prestados às } \\
\text { empresas }\end{array}$ & 1141 \\
\hline Secção M - Educação & 63 \\
\hline Secção N - Saúde e Acção social & 108 \\
\hline Secção O - Outras actividades e serviços colectivos, sociais e pessoais & 123 \\
\hline
\end{tabular}


A estrutura de custos fornecida foi a seguinte: custo das mercadorias vendidas e matérias consumidas, fornecimentos e serviços externos, custos com pessoal, amortizações de imobilizado corpóreo e incorpóreo, provisões, outros e custos e perdas operacionais, custos financeiros, custos e perdas extraordinários.

Para a análise a realizar, necessitávamos de distinguir os custos dos materiais directos, os custos da mão-de-obra directa, os custos industriais indirectos e custos não industriais indirectos.

Apesar da melhoria da informação, ainda continuámos a ter limitações, sendo necessário fixar alguns pressupostos.

Em relação ao custo dos materiais directos optamos por considerar que estes seriam iguais ao custo das mercadorias vendidas e matérias consumidas.

Quanto ao custo de mão-de-obra directa não poderíamos igualar aos custos com pessoal, pois existem sempre custos administrativos. Com base na revisão da literatura verificamos que a maioria considerava que os custos de mão-de-obra directa eram $15 \%$ dos custos totais de produção no sector da indústria. Consideramos, então, esta percentagem para calcular os custos de mão-de-obra directa alargando o pressuposto a todas as actividades económicas. Como não tínhamos disponível os custos de produção aplicamos os $15 \%$ sobre os custos operacionais para calcular o respectivo custo. Visto que nalgumas actividades económicas o valor dava superior aos custos com pessoal, considerámos então que o valor seria os custos com pessoal.

Posteriormente, para melhorarmos o estudo, aplicamos no sector da indústria transformadora as percentagens fornecidas no estudo de Alves (2002).

\section{RESULTADOS}

Segundo o estudo de Vokurka e Lummus (2001), devíamos calcular a percentagem dos gastos gerais de fabrico em relação ao custo de produção. Mas, se considerarmos que cada vez é mais premente a distribuição de todos os custos pelos produtos, como por exemplo os custos de distribuição, poderemos utilizar neste estudo os gastos gerais. É claro que Cooper e Kaplan (1998) consideram que os custos no nível de manutenção da empresa não são distribuídos e se isso acontecer é de algum modo arbitrário. Contudo, isso é um factor que já foi considerado no estudo de Vokurka e Lummus (2001) a nível de gastos gerais de fabrico onde referem que cerca de $10 \%$ dos custos são distribuídos de forma arbitrária. Percentagem que está em concordância com Glad (1993) que refere que apenas cerca de $90 \%$ dos custos são bem distribuídos pelos produtos. 
Porém, é preciso ter cuidado com a designação de gastos gerais. Existem diversas definições. Poderemos considerar que são todos os custos para além dos directos, ou, são os custos de produção que não estão relacionados directamente com os produtos, isto é, os gastos gerais de fabrico. Já Cooper e Kaplan (1998) consideram gastos gerais os custos que não estão incluídos em custos de produção, distribuição, marketing e vendas. Atkinson et al. (2001) realizaram uma classificação dos custos por funções segundo "Generally Accepted Accounting Principles" (GAAP). Os custos são distinguidos em industriais e não industriais. Por sua vez, os industriais poderão ser directos ou indirectos. Os não industriais subdividem-se em: distribuição, de venda, marketing, após vendas, investigação e desenvolvimento e gerais e administrativos. No nosso estudo, ao utilizarmos a designação gastos gerais, estamos a considerar a soma dos custos não industriais com os custos industriais indirectos a nível operacional. Ou seja, estamos a excluir da estrutura de custos os custos financeiros e os custos e perdas extraordinários.

Deste modo, calculámos as percentagens dos gastos gerais em relação aos custos operacionais, para as diferentes actividades económicas.

Ao observarmos os resultados, detectamos 88 actividades económicas pertencentes tanto ao sector do comércio como ao da indústria que têm gastos gerais inferiores a $15 \%$ dos custos operacionais.

Comparando com o estudo anterior, Gomes e Rodrigues (2003), temos um aumento das actividades que se situam abaixo dos $15 \%$, pois estas eram apenas três.

A desagregação até cinco dígitos mostrou mais as diversas naturezas de estrutura de custos em relação às actividades económicas. Ou melhor, as particularidades das actividades económicas anulam-se quando agregamos as actividades até três dígitos.

Outro factor que veio melhorar o estudo foi a utilização do custo de mão-de-obra directa. É que apesar de estar na moda dizer que os gastos gerais estão a aumentar em detrimento da mão-de-obra directa, esta, ainda, tem algum peso no custo de produção nalgumas actividades económicas.

Principiamos por observar as actividades a cinco dígitos pertencentes às actividades de três dígitos com gastos gerais inferiores a $15 \%$, no estudo de Gomes e Rodrigues (2003). Como podemos observar no quadro 8 as actividades de cinco dígitos, também, possuem gastos gerais inferiores a $15 \%$ apesar de algumas oscilações em termos percentuais. Aqui não verificamos alterações de estrutura de custos destas actividades. 


\section{Quadro 8}

Comparação das actividades de três dígitos com gastos gerais inferiores a $15 \%$ com as de cinco dígitos

\begin{tabular}{|c|c|c|c|}
\hline $\begin{array}{l}\text { Código } \\
\text { a três } \\
\text { dígitos }\end{array}$ & $\begin{array}{l}\% \text { de } \\
\text { Gastos } \\
\text { gerais }\end{array}$ & Actividades a cinco dígitos & $\begin{array}{ll}\% & \text { de } \\
\text { gastos } & \\
\text { gerais } & \\
\end{array}$ \\
\hline 505 & 7,52 & $\begin{array}{l}50500 \text { Comércio a retalho de combustíveis para } \\
\text { veículos a motor }\end{array}$ & 4,33 \\
\hline \multirow{5}{*}{512} & \multirow{5}{*}{12,37} & $\begin{array}{l}51211 \text { Comércio por grosso de cereais, sementes, } \\
\text { leguminosas e oleaginosas }\end{array}$ & 3,59 \\
\hline & & $\begin{array}{l}51212 \text { Comércio por grosso de alimentos para } \\
\text { animais }\end{array}$ & 11,27 \\
\hline & & 51220 Comércio por grosso de flores e plantas & 11,9 \\
\hline & & 51230 Comércio por grosso de animais vivos & 3,98 \\
\hline & & 51240 Comércio por grosso de peles e couro & 6,41 \\
\hline 501 & 12,62 & 50100 Comércio de veículos automóveis & 8,96 \\
\hline
\end{tabular}

O mesmo não acontece com as actividades económicas de Gomes e Rodrigues (2003) que tinham gastos gerais superiores a $15 \%$. No apêndice I podemos observar as actividades a cinco dígitos que possuem gastos gerais inferiores a $15 \%$ dos custos operacionais. Estas foram relacionadas com a percentagem dos gastos gerais das actividades económicas a três dígitos referidas em Gomes e Rodrigues (2003). Detectámos grandes diferenças a nível de estrutura de custos. A título de exemplo temos indústria do açúcar, a mediação e avaliação do imobiliário e produção de gelo cujas actividades a três dígitos tinham uma percentagem de gastos gerais de $50,54 \%, 62,42 \%$ e $84,14 \%$, respectivamente. Ao observarmos as diversas actividades económicas que fazem parte das actividades de três dígitos, verificámos uma diversidade a nível da estrutura de custos. Também, ao analisar a estrutura de custos de cada empresa pertencente à mesma actividade de cinco dígitos verificamos que a estrutura também é diversa. Como por exemplo 
podemos observar a estrutura de custos das empresas que fazem parte da actividade Administração de imóveis por conta de outrem, no quadro 9.

\section{Quadro 9}

Estrutura de custos das empresas pertencentes à actividade económica da administração de imóveis por conta de outrem.

\begin{tabular}{|c|c|c|c|c|c|c|}
\hline & $\begin{array}{l}\text { Custo das } \\
\text { mercadoria } \\
\text { s vendidas } \\
\text { e das } \\
\text { matérias } \\
\text { consumidas }\end{array}$ & $\begin{array}{l}\text { Fornecime } \\
\text { ntos e } \\
\text { serviços } \\
\text { externos }\end{array}$ & $\begin{array}{l}\text { Custos } \\
\text { com o } \\
\text { pessoal }\end{array}$ & $\begin{array}{l}\text { Amortizaçõe } \\
\text { s do } \\
\text { imobilizado } \\
\text { corpóreo e } \\
\text { incorpóreo }\end{array}$ & Provisões & $\begin{array}{l}\text { Outros } \\
\text { custos } \\
\text { perdas } \\
\text { operacionais }\end{array}$ \\
\hline 1 & $0,00 \%$ & $19.99 \%$ & $72,65 \%$ & $7,36 \%$ & $0.00 \%$ & $0,00 \%$ \\
\hline 2 & $8,31 \%$ & $49,72 \%$ & $40,44 \%$ & $1,52 \%$ & $0,00 \%$ & $0,00 \%$ \\
\hline 3 & $1,60 \%$ & $56,10 \%$ & $38,89 \%$ & $3,24 \%$ & $0,00 \%$ & $0,17 \%$ \\
\hline 4 & $0,00 \%$ & $31,34 \%$ & $65,14 \%$ & $3,51 \%$ & $0,00 \%$ & $0,01 \%$ \\
\hline 5 & $0,00 \%$ & $99,87 \%$ & $0,00 \%$ & $0,00 \%$ & $0,00 \%$ & $0,13 \%$ \\
\hline 6 & $1,99 \%$ & $25,68 \%$ & $37,07 \%$ & $33,97 \%$ & $1,12 \%$ & $0,16 \%$ \\
\hline 7 & $0,00 \%$ & $100,00 \%$ & $0,00 \%$ & $0,00 \%$ & $0,00 \%$ & $0,00 \%$ \\
\hline 8 & $0,00 \%$ & $100,00 \%$ & $0,00 \%$ & $0,00 \%$ & $0,00 \%$ & $0,00 \%$ \\
\hline 9 & $0,00 \%$ & $35,50 \%$ & $61,66 \%$ & $2,84 \%$ & $0,00 \%$ & $0,00 \%$ \\
\hline 10 & $0,00 \%$ & $28.84 \%$ & $0,00 \%$ & $71.16 \%$ & $0,00 \%$ & $0,00 \%$ \\
\hline 11 & $0,00 \%$ & $100,00 \%$ & $0,00 \%$ & $0,00 \%$ & $0,00 \%$ & $0,00 \%$ \\
\hline 12 & $0,00 \%$ & $61.09 \%$ & $0,00 \%$ & $38.91 \%$ & $0,00 \%$ & $0.00 \%$ \\
\hline 13 & $0,00 \%$ & $95,50 \%$ & $1,89 \%$ & $2.12 \%$ & $0,46 \%$ & $0.03 \%$ \\
\hline 14 & $0,00 \%$ & $97,83 \%$ & $2,07 \%$ & $0,08 \%$ & $0,01 \%$ & $0,01 \%$ \\
\hline 15 & $0,00 \%$ & $57.23 \%$ & $38,01 \%$ & $4,28 \%$ & $0,00 \%$ & $0,47 \%$ \\
\hline 16 & $0,00 \%$ & $99,38 \%$ & $0,00 \%$ & $0,00 \%$ & $0,00 \%$ & $0,62 \%$ \\
\hline
\end{tabular}

De modo a retirar algumas conclusões acerca dos três grandes sectores industriais, serviços e comércio observámos, pormenorizadamente, os dados.

No sector do comércio verificámos que existem actividades económicas desde os $2,08 \%$ de gastos gerais nos custos operacionais que é a 51110 Agentes de comércio por grosso de matérias-primas agrícolas e 
têxteis, animais vivos e produtos semiacabados até aos $85 \%$ de gastos gerais nos custos operacionais que é a 51130 Agentes de comércio por grosso de madeira e materiais de construção.

O sector da indústria também percorre um grande intervalo, a percentagem mais baixa de gastos gerais é de 1,99\% na 36635 Fabricação de fósforos e outros produtos de ignição e a mais alta é de $85 \%$ nas actividades 15613 Transformação de cereais e leguminosas, n.e. e 26140 Fabricação de fibras de vidro.

O sector dos serviços a percentagem de gastos gerais é mais alta, mas apesar de tudo ainda tem um grande intervalo. Inicia-se nos $24,6 \%$ com a 55306 Restaurantes, n. e. e termina com $100 \%$ na 55403 Bares e 60300 Transportes por oleodutos e gasodutos.

Analisando a informação baseada no critério de Bjonernak (1997) conseguimos chegar a conclusões similares. Segundo este autor, a distinção entre as empresas adoptantes e não adoptantes está à volta dos $70 \%$. Contudo, as actividades dentro dos três grandes sectores têm uma diversidade de situações como já tínhamos verificado. No sector do comércio temos um intervalo que inicia com 52410 o comércio a retalho de têxteis com $36,19 \%$ e finaliza com 52500 o comércio a retalho de artigos em segunda mão em estabelecimentos com $95,07 \%$. No sector da indústria iniciámos com a 36635 fabricação de fósforos com $38,13 \%$ até à 15333 Fabricação de doces e 15332 Secagem e desidratação de frutos e produtos hortícolas com $100 \%$. No dos serviços iniciámos com a 70310 Mediação e avaliação imobiliária com $51,42 \%$ e finaliza com $100 \%$ na 55403 Bares, 60300 Transportes por oleodutos e gasodutos e 71330 Aluguer de máquinas e equipamento de escritório.

Em suma, apesar de uma ligeira diferença das actividades que estão nos limites dos intervalos continuámos a estar perante a mesma situação, isto é, nos três grandes sectores as actividades económicas percorrem diversas estruturas de custos.

Só mostra que não é por pertencer ao sector dos serviços, comércio ou indústria que vai anular a aplicação do $\mathrm{CBA}$, no que diz respeito à variável estrutura de custos. Em todos os sectores existem actividades económicas propensas à implementação do CBA.

São conclusões que vieram anular as retiradas no estudo anterior "os subsectores mais propensos à aplicação do $\mathrm{CBA}$, os que possuem as percentagens mais altas de gastos gerais. Apurámos que todos pertencem ao sector de serviços. As actividades pertencentes a este sector são as que têm mais custos indirectos e uma diversidade de serviços.

Em suma, podemos dizer que a aplicabilidade do CBA no sector das empresas comerciais é questionada, no sector das empresas de serviços é 
importante, e, que o sector industrial está numa fase intermédia." (Gomes e Rodrigues, 2003:13)

Comparando a nossa análise com o estudo de Innes e Mitchell (1995) elaboramos a seguinte correspondência.

\section{Quadro 10}

Comparação com o estudo de Innes e Mitchell (1995)

\begin{tabular}{|c|c|c|c|c|}
\hline $\begin{array}{l}\text { Actividades } \\
\text { económicas de Innes e } \\
\text { Mitchell (1995) }\end{array}$ & $\begin{array}{l}\text { Nossa } \\
\text { percentage } \\
\text { m de } \\
\text { gastos } \\
\text { gerais } \\
\end{array}$ & $\begin{array}{l}\text { Percentagem } \\
\text { de gastos gerais } \\
\text { segundo } \\
\text { Bjonernak } \\
(1997) \\
\end{array}$ & $\begin{array}{l}N^{0} \quad \text { de } \\
\text { empresas } \\
\text { que } \\
\text { utilizam o } \\
\text { CBA } \\
\end{array}$ & $\begin{array}{l}\mathbf{N}^{\circ} \quad \text { de } \\
\text { empresas } \\
\text { que } \\
\text { rejeitaram } \\
\text { o CBA } \\
\end{array}$ \\
\hline Fabricação Cerveja & $46,81 \%$ & $75,48 \%$ & 2 & \\
\hline $\begin{array}{l}\text { Fabricação de produtos } \\
\text { químicos }\end{array}$ & $29.58 \%$ & $66,35 \%$ & 2 & 2 \\
\hline Construção & $53,51 \%$ & $79,92 \%$ & 2 & 2 \\
\hline Electricidade & $39,94 \%$ & $81,91 \%$ & 3 & 1 \\
\hline $\begin{array}{l}\text { Equipamento } \\
\text { electrónico e eléctrico }\end{array}$ & $33,83 \%$ & $68,68 \%$ & 4 & 1 \\
\hline Indústria extractiva & $70,99 \%$ & $82,56 \%$ & & 1 \\
\hline Indústrias alimentares & $25,79 \%$ & $69,64 \%$ & 3 & 1 \\
\hline $\begin{array}{l}\begin{array}{l}\text { Actividades de saúde } \\
\text { humana }\end{array} \\
\text { he }\end{array}$ & $61,78 \%$ & $80,46 \%$ & 3 & 2 \\
\hline $\begin{array}{l}\text { Materiais industriais, } \\
\text { engenharia e metais }\end{array}$ & $40,12 \%$ & $72,79 \%$ & 8 & 13 \\
\hline Alojamento & $70,37 \%$ & $77,65 \%$ & & 1 \\
\hline Media & $84,76 \%$ & $84,96 \%$ & 1 & 2 \\
\hline Impressão & $50,41 \%$ & $77,07 \%$ & 1 & 1 \\
\hline Retalho & $19,1 \%$ & $62,6 \%$ & 4 & 1 \\
\hline Telecomunicações & $77,27 \%$ & $85,84 \%$ & 2 & 1 \\
\hline Fabricação de têxteis & $21,51 \%$ & $70,63 \%$ & 2 & \\
\hline Indústria do tabaco & $35.49 \%$ & $70,29 \%$ & 1 & \\
\hline $\begin{array}{l}\text { Distribuição } \\
\text { transporte }\end{array}$ & $79,3 \%$ & $84,09 \%$ & 3 & 2 \\
\hline Água & $46,44 \%$ & $75,66 \%$ & 3 & \\
\hline
\end{tabular}

Dos sectores analisados por Innes e Mitchell (1995), os que estão apresentados no quadro anterior foram os que nós conseguimos fazer a correspondência com o nosso estudo. Todas estas actividades apresentam uma percentagem de gastos gerais acima dos $19 \%$, o que demonstra que necessitam de CBA. Contudo, no que respeita à actividade de retalho, é necessário um certo cuidado. Tudo depende do tipo de retalho a que se referem Innes e Mitchell (1995), pois existem actividades com gastos 
somente ênfase atenção às alterações das actividades que mudam de lado, ou seja, tinham percentagens de gastos gerais inferiores a $15 \%$, mostrando a necessidade de outros estudos para verificar os benefícios da implementação do CBA, e passaram a ter percentagem superior a $15 \%$, desaparecendo as dúvidas em relação ao CBA, no que respeita à estrutura de custos. Sucedeu apenas em cinco actividades. Nada de significativo.

\section{Quadro 11}

Actividades económicas que ultrapassaram a fronteira dos $15 \%$ dos gastos gerais

\begin{tabular}{|l|l|l|}
\hline Actividades económicas & $\begin{array}{l}\text { Percentagem de } \\
\text { gastos gerais nos } \\
\text { custos operacionais } \\
\text { considerando a } \\
\text { percentagem } \\
\text { MOD de 15\% }\end{array}$ & $\begin{array}{l}\text { Percentagem de gastos } \\
\text { gerais nos custos } \\
\text { operacionais considerando } \\
\text { a percentagem de MOD de } \\
\text { Alves (2002) }\end{array}$ \\
\hline 15110 Abate de gado & $11,77 \%$ & $15,63 \%$ \\
\hline 15120 Abate de aves e de coelhos & $14,84 \%$ & $15,64 \%$ \\
\hline $\begin{array}{l}15334 \text { Descasque e transformação de } \\
\text { frutos de casca rija comestíveis produtos }\end{array}$ & $13,14 \%$ & $15,66 \%$ \\
\hline $\begin{array}{l}15893 \text { Fabricação de outros produtos } \\
\text { alimentares diversos, n.e. }\end{array}$ & $14,89 \%$ & $22,28 \%$ \\
\hline 24630 Fabricação de óleos essenciais & $13,95 \%$ & $17,26 \%$ \\
\hline
\end{tabular}

Algo detectado é que em muitas actividades económicas a percentagem da mão-de-obra directa em relação aos custos totais, retirada de Alves (2002), não confere com os nossos dados. No apêndice II podemos observar as actividades em que a percentagem dos custos com pessoal sobre os custos totais é inferior à percentagem da mão-de-obra de Alves (2002). Podemos tecer várias explicações. Mas, de modo a não contestar a fiabilidade da informação retirada de Alves (2002) nem a fornecida pelo Banco Portugal, o mais natural seria argumentar que as actividades económicas desagregadas apresentam estrutura de custos diferentes mesmo que a sua actividade principal seja igual. Podemos afirmar que empresas pertencentes à mesma actividade económica de cinco dígitos têm estruturas de custos diferentes.

Decidimos que seria oportuno analisar, em pormenor, as actividades em questão. A actividade 15 subdivide-se em 47 actividades em que 35 respeitam os $7 \%$. A actividade 17 subdivide-se em 26 actividades em que 10 respeitam os $23 \%$. Na actividade 18 os $15 \%$ são respeitados em todas as actividades. A actividade 20 subdivide-se em 7 actividades em que 5 respeitam os $17 \%$. Na actividade 21 os $9 \%$ são respeitados em todas as actividades. A actividade 22 subdivide-se em 11 actividades em que 8 respeitam os $17 \%$. A actividade 24 subdivide-se em 24 actividades em 
que 21 respeitam os $10 \%$. A actividade 25 subdivide-se em 7 actividades em que 3 respeitam os $20 \%$. A actividade 26 subdivide-se em 29 actividades em que 13 respeitam os $22 \%$. A actividade 28 subdivide-se em 21 actividades em que 9 respeitam os $27 \%$. A actividade 29 subdivide-se em 28 actividades em que 23 respeitam os $15 \%$. Na actividade 31 os $7 \%$ são respeitados em todas as actividades. A actividade 34 subdivide-se em 3 actividades em que 2 respeitam os $9 \%$. A actividade 35 subdivide-se em 8 actividades em que nenhuma respeita os $40 \%$. A actividade 36 subdivide-se em 21 actividades em que 14 respeitam os $21 \%$.

O problema é mais acentuado nas actividades cuja percentagem de mão-de-obra é superior ou igual aos $20 \%$. O caso mais flagrante é a actividade $35 \mathrm{em}$ que Alves (2002) refere uma percentagem de $40 \%$ a qual não é atingida por nenhuma das actividades desagregadas. Será que nestes dois anos a estrutura de custos modificou-se ou as empresas não têm bem presente a sua percentagem de mão-de-obra directa?

Um outro aspecto interessante é o peso dos materiais. Existem actividades económicas em que o peso dos materiais é enorme. No quadro seguinte temos as actividades económicas que possuem uma percentagem de materiais acima dos $90 \%$.

\section{Quadro 12}

Actividades económicas cuja percentagem dos materiais é superior a $90 \%$

\begin{tabular}{|l|l|l|l|}
\hline Código & Descrição da actividade & $\begin{array}{l}\text { Percentagem do } \\
\text { custo dos materiais }\end{array}$ & $\begin{array}{l}\text { Percentagem dos } \\
\text { gastos gerais }\end{array}$ \\
\hline 15912 & $\begin{array}{l}\text { Fabricação de aguardentes } \\
\text { não preparadas }\end{array}$ & 90,22 & 7 \\
\hline 36635 & $\begin{array}{l}\text { Fabricação de fósforos e } \\
\text { outros produtos de ignição }\end{array}$ & 94,77 & 1,99 \\
\hline 50500 & $\begin{array}{l}\text { Comércio a retalho de } \\
\text { combustível para veículos a } \\
\text { motor }\end{array}$ & 92,12 & 4,33 \\
\hline 51110 & $\begin{array}{l}\text { Agentes de comércio por } \\
\text { grosso de matérias-primas } \\
\text { agricolas e texxteis, animais } \\
\text { vivos produtos } \\
\text { semiacabados }\end{array}$ & 2,08 \\
\hline 51211 & $\begin{array}{l}\text { Comércio por grosso de } \\
\text { cereais, sementes, } \\
\text { leguminosas e oleaginosas }\end{array}$ & 95,46 & 3,59 \\
\hline 51230 & $\begin{array}{l}\text { Comércio por grosso de } \\
\text { animais vivos }\end{array}$ & 94,54 & 3,98 \\
\hline 51350 & $\begin{array}{l}\text { Comércio por grosso de } \\
\text { tabaco }\end{array}$ & 95,99 & 3,21 \\
\hline 51562 & $\begin{array}{l}\text { Comércio por grosso de } \\
\text { cortiça em bruto }\end{array}$ & 93,62 & 4,39 \\
\hline 52500 & $\begin{array}{l}\text { Comércio a retalho de leite e } \\
\text { derivados }\end{array}$ & 90,69 & 8,85 \\
\hline
\end{tabular}


Como é natural encontrámos muitas actividades pertencentes ao sector do comércio. Mas, temos duas actividades pertencentes ao sector da indústria com uma alta percentagem de custo de matérias. Quando se está a falar em custear os produtos talvez fosse mais importante analisar esta componente de custo do que os gastos gerais, que são ínfimos.

Duarte (2002) realizou um estudo em Portugal onde apurou onze empresas que utilizavam o CBA ou estavam a implementá-lo. Seguidamente, vamos relacionar as respectivas actividades económicas com a respectiva estrutura de custos.

\section{Quadro 13}

Percentagem de gastos gerais nas actividades económicas com CBA em Portugal

\begin{tabular}{|l|l|l|}
\hline Actividades económicas & $\begin{array}{l}\text { Percentagem } \\
\text { Gastos gerais }\end{array}$ & $\begin{array}{l}\text { de } \\
\text { Gastostagem de } \begin{array}{c}\text { gerais } \\
\text { Bjonernak (1997) }\end{array}\end{array}$ \\
\hline 64200 - Telecomunicações & $77,27 \%$ & $85,84 \%$ \\
\hline $\begin{array}{l}29130 \text { - Fabricação de torneiras e de } \\
\text { válvulas }\end{array}$ & $29,03 \%$ & $65,93 \%$ \\
\hline $\begin{array}{l}24661 \text { - Fabricação de produtos } \\
\text { químicos auxiliares para uso industrial }\end{array}$ & $39,06 \%$ & $76,88 \%$ \\
\hline $\begin{array}{l}26131 \text { - Fabricação de vidro de } \\
\text { embalagem }\end{array}$ & $49,15 \%$ & $76,62 \%$ \\
\hline $\begin{array}{l}64110 \text { Actividades dos correios } \\
\text { nacionais }\end{array}$ & $83,30 \%$ & $84,74 \%$ \\
\hline $\begin{array}{l}40220 \text { - Distribuição e comércio de } \\
\text { combustiveis gasosos por conduta }\end{array}$ & $27,59 \%$ & $76,11 \%$ \\
\hline $\begin{array}{l}40120 \text { - Transporte de } \\
\text { electricidade/distribuição e comércio de } \\
\text { electricidade }\end{array}$ & $16,38 \%$ & $68,94 \%$ \\
\hline 62100 - Transportes aéreos regulares & $80,97 \%$ & $84,37 \%$ \\
\hline $\begin{array}{l}13202-\text { Extração e preparação de } \\
\text { minérios de estanho }\end{array}$ & $80,16 \%$ & $84,24 \%$ \\
\hline $\begin{array}{l}34300-\text { Fabricação de componentes e } \\
\text { acessórios para veículos automóveis e } \\
\text { seus motores }\end{array}$ & $19,83 \%$ & $60,96 \%$ \\
\hline
\end{tabular}

Seguindo o critério definido por Vokurka e Lummus (2001) verificamos que todas as actividades económicas possuem uma percentagem de gastos gerais de fabrico superior a $15 \%$. Também, estão em convergência com a regra de "Willie Sutton". No fundo, o critério relacionado com a estrutura de custos está cumprido, apesar de ser necessário analisar a estrutura de custos de cada empresa que poderá ser 
diferente da média do sector. Em relação ao critério definido por Bjonernak (1997) encontramos três actividades que estão abaixo dos $70 \%$. Nesse estudo, em termos médios, as empresas com essa percentagem não eram utilizadoras de CBA. Seria essencial o apuramento da percentagem dos gastos gerais empresa a empresa. Faltam apurar os outros determinantes que levaram a esta opção, pois já verificamos que o critério em causa não é suficiente para as empresas tomarem a decisão de implementarem o CBA.

Em suma, depois deste estudo verificámos que pertencer à indústria, comércio ou serviços não é determinante para a aplicação do CBA. Dentro destes sectores encontrámos actividades económicas de naturezas diferentes, desagregadas até cinco dígitos. Se formos observar empresa a empresa de certeza que encontraremos características diferentes apesar de pertencerem à mesma actividade.

Um outro ponto a focar é a questão do custo dos materiais que é muito elevado nalgumas actividades. Se o CBA for aplicado nestas actividades deverá dedicar muita atenção a esta componente.

No que respeita à implementação do $\mathrm{CBA}$, a estrutura de custos não dá certezas. É necessário a contribuição de mais factores.

Depois de alguma investigação Cotton et al. (2003) chegaram à conclusão que o tamanho da empresa está relacionado com a implementação do CBA. O CBA é mais implementado nas grandes empresas do que nas pequenas.

Naraynan e Sarkar (1999) defendem que para implementar o CBA numa empresa é necessário realizar várias análises. Além das regras já definidas por Kaplan e Cooper, dizem que é necessário abordar outros aspectos. Como por exemplo, depende do tipo de mercado em que estamos inseridos. Num ambiente de equilíbrio com expectativas racionais, os gastos gerais e a variação da procura de serviços pelos clientes estão reflectidos, eficientemente, nos preços de mercado. Neste caso, os preços servem de substitutos à informação dos sistemas de custos internos. Um outro aspecto é a situação em que os gestores intuitivamente conseguem perceber os padrões de consumo dos recursos sem ser necessário a utilização de um sistema de custos formal.

Contudo, convém referir que para todas as actividades económicas aqui analisadas é importante a implementação do CBA, excepto para as que estão abaixo dos $15 \%$. Verificamos que é generalizado nas actividades económicas altas percentagens de gastos gerais, excepto naquelas em que o custo dos materiais é importante. Podemos justificar esta situação através das transformações que têm ocorrido no nosso meio envolvente: novas tecnologias, automatização crescente dos processos produtivos, informatização, globalização, competitividade e instabilidade dos mercados. É de salientar que, também, está a existir uma 
transferência de custos de produção para outras áreas funcionais, como por exemplo investigação e desenvolvimento, distribuição, etc. Só nos mostra que muitas empresas estão com dificuldades na imputação dos custos visto os sistemas de custeio estarem obsoletos, ou seja, estão direccionados para outra realidade. Torna-se urgente a substituição pelo CBA.

\section{CONCLUSÃO}

Este estudo propunha-se a relacionar a estrutura de custos das actividades económicas com o CBA. Através de uma revisão da literatura, verificámos que a componente mais elevada na estrutura de custos é o custo dos materiais e não os gastos gerais de fabrico. Realmente, a mão-de-obra directa tem vindo a diminuir a sua importância. Em termos gerais, na indústria, situa-se nos $15 \%$. Também, verificámos que apesar dos custos de mão-de-obra terem pouco peso, as empresas utilizam em demasia as bases de imputação horas homem e custo de mão-de-obra. O que é fulcral, é a afectação de custos relacionados com os materiais como por exemplo a armazenagem, inspecção através de bases relacionadas com a mão-de-obra directa.

O CBA está relacionado com a estrutura de custos na medida em que se defende que uma empresa com elevados gastos gerais de fabrico é propensa à sua implementação. Temos a regra de "Willie Sutton", o estudo de Vokurka e Lummus (2001) e o de Bjonernak (1997).

No estudo, por nós realizado, verificamos que tanto no sector dos serviços, da indústria e do comércio existem actividades com altos gastos gerais, por consequência propensas ao CBA. Somente, no sector dos serviços é que não existem actividades económicas com gastos gerais inferiores aos $15 \%$.

$\mathrm{Na}$ actividade económica o cálculo da percentagem dos gastos gerais é realizada em termos médios, isto é, dentro desta podemos encontrar estruturas de custos diferentes, o que viemos a confirmar. Logo, a conclusão atrás retirada poderá ser contestada se a média não for observada e sim a estrutura de custos de cada empresa.

Ao compararmos com o estudo de Innes e Mitchell (1995) verificámos que não existe relação entre as percentagens dos gastos gerais das actividades económicas e as rejeições pelas empresas. Tanto as empresas que pertencem a uma actividade económica com altas percentagens de gastos gerais como as pertencentes a actividades económicas com baixas percentagens rejeitam o CBA. Só demonstra que não existe um procedimento geral dentro de cada actividade económica. Logo, não 
podemos afirmar que pertencer a uma determinada actividade económica temos uma determinada estrutura de custos e, por isso, deve aplicar ou não o CBA. Quando muito podemos fazer uma aproximação, mas já verificámos que existem desvios. Todavia, deverão existir outras variáveis pertencentes a uma actividade económica que poderão influenciar, como por exemplo normas reguladoras. No fundo, além da estrutura de custos, as empresas têm comportamentos diversos que dependem da sua cultura, história, do contexto onde estão inseridas, da disponibilidade dos recursos, da competitividade do sector, do tamanho, etc.

Um outro ponto a focar, é o cuidado que é necessário ter na componente de custo dos materiais, pois nalgumas actividades económicas apresenta um grande peso. Nas ligadas ao comércio era previsível, mas na indústria encontramos duas em que o custo com os materiais é superior a $90 \%$.

Em relação às actividades económicas que já possuem o $\mathrm{CBA}$ em Portugal, todas elas têm uma percentagem de gastos gerais superior aos $15 \%$. O critério relacionado com a estrutura de custos está cumprido.

Como conclusão, podemos referir que não existe uma linearidade entre os gastos gerais e o CBA, porque, apesar da potencialidade existente, muitas empresas não optam pelo CBA. Pertencer a uma actividade económica não implica a utilização do CBA se estivermos a analisar a variável estrutura de custos. Porém, é premente a realização de um estudo mais profundo às actividades económicas de modo a explorar se existem outras variáveis inerentes às mesmas que implicarão a utilização do CBA. Finalmente, as próprias empresas têm características intrínsecas, as quais influenciam as técnicas de contabilidade de gestão a utilizar. Também, as empresas consideram que existem outros factores que são mais prementes que o elevado montante de gastos gerais. Logo, num estudo futuro seria importante analisar quais são os determinantes que influenciam as empresas a utilizar o CBA. Como por exemplo temos a estrutura organizacional, a estratégia, a cultura, a diversidade de produtos, a competitividade, o tamanho, descentralização, o capital intelectual, a comunicação, etc. 


\section{Apêndices}

\section{Apêndice I}

Comparação das actividades a cinco dígitos com percentagem inferior aos $15 \%$

\begin{tabular}{|c|c|c|}
\hline Código & Descrição da actividade & \begin{tabular}{|lrr}
$\begin{array}{l}\text { Percentagem } \\
\text { actividade }\end{array}$ & da \\
dígitos & três \\
\end{tabular} \\
\hline 01210 & Bovinicultora & $30,18 \%$ \\
\hline 15110 & Abate de gado & \multirow[t]{2}{*}{$27,21 \%$} \\
\hline 15120 & Abate de aves e de coelhos & \\
\hline 15201 & Preparação de produtos da pesca e da aquicultura & \multirow[t]{3}{*}{$24.94 \%$} \\
\hline 15202 & Congelação de produtos da pesca e da aquicultura & \\
\hline 15204 & $\begin{array}{l}\text { Secagem, salga e outras actividades de transformação de } \\
\text { produtos da pesca e da aquicultura }\end{array}$ & \\
\hline 15333 & Fabricação de doces, compotas, geleias e marmelada & \multirow[t]{2}{*}{$44.83 \%$} \\
\hline 15334 & $\begin{array}{l}\begin{array}{l}\text { Descasque e transformação de frutos de casca rija } \\
\text { comestíveis }\end{array} \\
\end{array}$ & \\
\hline 15411 & Produção de óleos e gorduras animais brutos & \multirow[t]{3}{*}{$22.72 \%$} \\
\hline 15413 & Produção de óleos vegetais brutos & \\
\hline 15420 & Refinação de óleos e gorduras & \\
\hline 15710 & Fabricação de alimentos para animais de criação & $19.59 \%$ \\
\hline 15830 & Indústria do açúcar & \multirow[t]{2}{*}{$50,54 \%$} \\
\hline 15893 & Fabricação de outros produtos alimentares diversos, N.E. & \\
\hline 15912 & Fabricação de aguardentes não preparadas & \multirow[t]{2}{*}{$44.81 \%$} \\
\hline 15920 & Fabricação de álcool etílico de fermentação & \\
\hline 20400 & Fabricação de embalagens de madeira & $32,99 \%$ \\
\hline 20522 & Indústria da cortiça & $26,05 \%$ \\
\hline 23200 & Fabricação de produtos petrolíferos refinados & $17.55 \%$ \\
\hline 24141 & Fabricação de resinosos e seus derivados & $39,01 \%$ \\
\hline 24630 & Fabricação de óleos essenciais & $42,31 \%$ \\
\hline 27220 & Fabricação de tubos de aço & $20,11 \%$ \\
\hline 27320 & Laminagem a frio de arco ou banda & \multirow[t]{3}{*}{$26.08 \%$} \\
\hline 27330 & Perfilagem a frio & \\
\hline 27350 & Siderurgia e fabricação de ferro ligas & \\
\hline 29601 & Fabricação de armas de caça, de desporto e defesa & $37,24 \%$ \\
\hline 32300 & $\begin{array}{l}\text { Fabricação de aparelhos receptores e material de rádio e } \\
\text { de televisão, aparelhos de gravação ou de reprodução de } \\
\text { som e imagens e material associado }\end{array}$ & $26,48 \%$ \\
\hline
\end{tabular}




\begin{tabular}{|c|c|c|}
\hline 34100 & Fabricação de veículos automóveis & $22 \%$ \\
\hline 36635 & Fabricação de fósforos e outros produtos de ignição & $44.59 \%$ \\
\hline 40302 & Produção de gelo & $84,14 \%$ \\
\hline 50300 & $\begin{array}{l}\begin{array}{l}\text { Comércio de peças e acessórios para veículos } \\
\text { automóveis }\end{array} \\
\end{array}$ & $24,37 \%$ \\
\hline 50401 & $\begin{array}{l}\text { Comércio por grosso e a retalho de motociclos, de suas } \\
\text { peças e acessórios }\end{array}$ & $17.66 \%$ \\
\hline 50402 & $\begin{array}{l}\text { Manutenção e reparação de motociclos, de suas peças e } \\
\text { acessórios }\end{array}$ & $17.66 \%$ \\
\hline 51110 & $\begin{array}{l}\text { Agentes de comércio por grosso de matérias-primas } \\
\text { agrícolas e têxteis, animais vivos e produtos } \\
\text { semiacabados }\end{array}$ & $29.74 \%$ \\
\hline 51170 & $\begin{array}{l}\text { Agentes do comércio por grosso de produtos } \\
\text { alimentares, bebidas e tabaco }\end{array}$ & \\
\hline 51311 & $\begin{array}{l}\text { Comércio por grosso de fruta e de produtos hortícolas, } \\
\text { excepto batata }\end{array}$ & $16.82 \%$ \\
\hline 51312 & Comércio por grosso de batata & \\
\hline 51320 & $\begin{array}{l}\text { Comércio por grosso de carne e de produtos à base de } \\
\text { carne }\end{array}$ & \\
\hline 51342 & Comércio por grosso de bebidas não alcoólicas & \\
\hline 51350 & Comércio por grosso de tabaco & \\
\hline 51361 & Comércio por grosso de açúcar & \\
\hline 51381 & Comércio por grosso de peixe, crustáceos e moluscos & \\
\hline 51382 & Comércio por grosso de outros produtos alimentares, n.e. & \\
\hline 51390 & $\begin{array}{l}\text { Comércio por grosso não especializado de produtos } \\
\text { alimentares, bebidas e tabaco }\end{array}$ & \\
\hline 51410 & Comércio por grosso de têxteis & $29,4 \%$ \\
\hline 51422 & Comércio por grosso de calçado & \\
\hline 51460 & Comércio por grosso de produtos farmaceuticos & \\
\hline 51471 & Comércio por grosso de artigos de papelaria & \\
\hline 51510 & $\begin{array}{l}\text { Comércio por grosso de combustíveis líquidos, sólidos, } \\
\text { gasosos e produtos derivados }\end{array}$ & $20.12 \%$ \\
\hline 51520 & Comércio por grosso de minérios e de metais & \\
\hline 51531 & $\begin{array}{l}\text { Comércio por grosso de madeira em bruto e de produtos } \\
\text { derivados }\end{array}$ & \\
\hline 51532 & $\begin{array}{l}\text { Comércio por grosso de materiais de construção e } \\
\text { equipamento sanitário }\end{array}$ & \\
\hline 51540 & $\begin{array}{l}\text { Comércio por grosso de ferragens, ferramentas manuais } \\
\text { e artigos para canalizações e aquecimento }\end{array}$ & \\
\hline 51550 & Comércio por grosso de produtos químicos & \\
\hline
\end{tabular}




\begin{tabular}{|c|c|c|}
\hline 51561 & $\begin{array}{l}\text { Comércio por grosso de fibras têxteis naturais, artificiais } \\
\text { e sintéticas }\end{array}$ & \\
\hline 51562 & Comércio por grosso de cortiça em bruto & \\
\hline 51563 & Comércio por grosso de outros bens intermedios & \\
\hline 51571 & $\begin{array}{l}\text { Comércio por grosso de sucatas e de desperdícios } \\
\text { metálicos }\end{array}$ & \\
\hline 51573 & Comércio por grosso de desperdícios de materiais, n.e. & \\
\hline 51820 & $\begin{array}{l}\text { Comércio por grosso de máquinas para a indústria } \\
\text { extractiva, construção e engenharia civil }\end{array}$ & \multirow[t]{2}{*}{$26,88 \%$} \\
\hline 51880 & $\begin{array}{l}\text { Comércio por grosso de máquinas agrícolas e outros } \\
\text { equipamentos agrícolas }\end{array}$ & \\
\hline 51900 & Comércio por grosso, n.e. & $25,21 \%$ \\
\hline 52120 & $\begin{array}{l}\text { Comércio a retalho em estabelecimentos não } \\
\text { especializados sem predominância de produtos } \\
\text { alimentares, bebidas ou tabaco }\end{array}$ & $21,37 \%$ \\
\hline 52210 & Comércio a retalho de fruta e de produtos hortícolas & \multirow[t]{5}{*}{$17.97 \%$} \\
\hline 52220 & $\begin{array}{l}\text { Comércio a retalho de carne e de produtos à base de } \\
\text { carne }\end{array}$ & \\
\hline 52230 & Comércio a retalho de peixe, crustáceos e moluscos & \\
\hline 52271 & Comércio a retalho de leite e derivados & \\
\hline 52272 & $\begin{array}{l}\text { Outro comércio a retalho de produtos alimentares em } \\
\text { estabelecimentos especializados n.e. }\end{array}$ & \\
\hline 52310 & Comércio a retalho de produtos farmaceuticos & \multirow[t]{2}{*}{$19,63 \%$} \\
\hline 52320 & Comércio a retalho de artigos médicos e ortopédicos & \\
\hline 52410 & Comércio a retalho de têxteis & \multirow[t]{6}{*}{$26,93 \%$} \\
\hline 52432 & Comércio a retalho de marroquinaria e artigos de viagem & \\
\hline 52462 & $\begin{array}{l}\begin{array}{l}\text { Comércio a retalho de tintas, vernizes e produtos } \\
\text { similares }\end{array} \\
\end{array}$ & \\
\hline 52481 & $\begin{array}{l}\text { Comércio a retalho de máquinas e de outro material de } \\
\text { escritório }\end{array}$ & \\
\hline 52483 & $\begin{array}{l}\begin{array}{l}\text { Comércio a retalho de relógios e de artigos de } \\
\text { ourivesaria }\end{array} \\
\end{array}$ & \\
\hline 52484 & Comércio a retalho de brinquedos e jogos & \\
\hline 52500 & $\begin{array}{l}\text { Comércio a retalho de artigos em segunda mão em } \\
\text { estabelecimentos }\end{array}$ & $37.56 \%$ \\
\hline 52621 & $\begin{array}{l}\text { Comércio a retalho em bancas, feiras e unidades móveis } \\
\text { de venda de produtos alimentares e bebidas }\end{array}$ & \multirow[t]{2}{*}{$33.08 \%$} \\
\hline 52622 & $\begin{array}{l}\text { Comércio a retalho em bancas, feiras e unidades móveis } \\
\text { de venda de vestuário, tecidos, calçado, malas e similares }\end{array}$ & \\
\hline 70310 & Mediação e avaliação imobiliária & $62,42 \%$ \\
\hline
\end{tabular}




\section{Apêndice II}

\begin{tabular}{|c|c|c|}
\hline Actividades económicas & $\begin{array}{l}\text { Percentagem dos custos } \\
\text { com pessoal em relação aos } \\
\text { custos totais }\end{array}$ & $\begin{array}{l}\text { Percentagem de } \text { Alves } \\
(2002)\end{array}$ \\
\hline 15202 & 5,52 & 7 \\
\hline 15204 & 4,01 & 7 \\
\hline 15332 & 0 & 7 \\
\hline 15333 & 0 & 7 \\
\hline 15411 & 6.57 & 7 \\
\hline 15413 & 2.46 & 7 \\
\hline 15420 & 4,02 & 7 \\
\hline 15612 & 5.19 & 7 \\
\hline 15710 & 5,38 & 7 \\
\hline 15830 & 6,58 & 7 \\
\hline 15912 & 2,69 & 7 \\
\hline 15970 & 3,3 & 7 \\
\hline 17110 & 18,10 & 23 \\
\hline 17130 & 10,53 & 23 \\
\hline 17150 & 14,78 & 23 \\
\hline 17170 & 13,81 & 23 \\
\hline 17210 & 18,75 & 23 \\
\hline 17230 & 18,74 & 23 \\
\hline 17240 & 10,09 & 23 \\
\hline 17250 & 17,18 & 23 \\
\hline 17303 & 18,79 & 23 \\
\hline 17400 & 15,22 & 23 \\
\hline 17510 & 22,47 & 23 \\
\hline 17521 & 22,81 & 23 \\
\hline 17522 & 15,29 & 23 \\
\hline 17530 & 19,35 & 23 \\
\hline 17544 & 13,72 & 23 \\
\hline 17600 & 15,14 & 23 \\
\hline 20101 & 14,61 & 17 \\
\hline 20102 & 12,66 & 17 \\
\hline 20201 & 8,76 & 17 \\
\hline 20202 & 7,67 & 17 \\
\hline 20400 & 6,97 & 17 \\
\hline 20521 & 10,32 & 17 \\
\hline 20522 & 10,59 & 17 \\
\hline 22110 & 16,54 & 17 \\
\hline 22140 & 16,74 & 17 \\
\hline 22310 & 14,98 & 17 \\
\hline 24141 & 9,26 & 10 \\
\hline 24143 & 4,77 & 10 \\
\hline 24160 & 7,53 & 10 \\
\hline 25110 & 14,67 & 20 \\
\hline 25210 & 13,31 & 20 \\
\hline 25220 & 12,66 & 20 \\
\hline
\end{tabular}




\begin{tabular}{|c|c|c|}
\hline 25230 & 19,88 & 20 \\
\hline 26110 & 13,41 & 22 \\
\hline 26120 & 16,42 & 22 \\
\hline 26131 & 18,06 & 22 \\
\hline 26220 & 20,72 & 22 \\
\hline 26260 & 20,48 & 22 \\
\hline 26302 & 19.83 & 22 \\
\hline 26403 & 14,53 & 22 \\
\hline 26510 & 9,58 & 22 \\
\hline 26522 & 6,54 & 22 \\
\hline 26610 & 20,85 & 22 \\
\hline 26630 & 8,12 & 22 \\
\hline 26640 & 14.51 & 22 \\
\hline 26650 & 20,42 & 22 \\
\hline 26660 & 14,41 & 22 \\
\hline 26703 & 21,79 & 22 \\
\hline 26820 & 10,78 & 22 \\
\hline 28110 & 23,41 & 27 \\
\hline 28120 & 25,59 & 27 \\
\hline 28210 & 19,01 & 27 \\
\hline 28401 & 12.54 & 27 \\
\hline 28510 & 18,73 & 27 \\
\hline 28630 & 24,45 & 27 \\
\hline 28720 & 13,71 & 27 \\
\hline 28730 & 12.15 & 27 \\
\hline 28741 & 15,88 & 27 \\
\hline 28743 & 19,59 & 27 \\
\hline 28751 & 21,17 & 27 \\
\hline 28752 & 24,82 & 27 \\
\hline 29510 & 13,12 & 15 \\
\hline 29562 & 8,05 & 15 \\
\hline 29601 & 13,76 & 15 \\
\hline 29710 & 12,51 & 15 \\
\hline 29720 & 11.7 & 15 \\
\hline 34100 & 5,53 & 9 \\
\hline 35111 & 36,01 & 40 \\
\hline 35112 & 30,98 & 40 \\
\hline 35120 & 17,35 & 40 \\
\hline 35200 & 31,39 & 40 \\
\hline 35300 & 32,7 & 40 \\
\hline 35410 & 33,32 & 40 \\
\hline 35420 & 19,26 & 40 \\
\hline 35500 & 18,53 & 40 \\
\hline 36110 & 15,72 & 21 \\
\hline 36221 & 16,03 & 21 \\
\hline 36222 & 17,93 & 21 \\
\hline 36223 & 11,68 & 21 \\
\hline 36400 & 12,08 & 21 \\
\hline
\end{tabular}




\begin{tabular}{|l|l|l|}
\hline 36620 & 14,59 & 21 \\
\hline 36635 & 3,20 & 21 \\
\hline
\end{tabular}




\section{REFERÊNCIAS BIBLIOGRÁFICAS}

Alves, Maria do Céu, Decisores e informação contabilística - sua influência nas decisões empresariais, Tese de doutoramento, Fevereiro 2002, Covilhã.

Atkinson, Anthony, Banker, Rajiv, Kaplan, Robert e Young, Mark, Management Accounting, Prentice Hall, 2001.

Bjornenak, Trond, "Diffusion and accounting: the case of ABC in Norway", Management Accounting Research, 8, 1997, pp. 3-17.

Christensen, Linda e Sharp, Douglas, "How ABC can add value to decision making”, Management Accounting, 74, n 11 (Maio), 1993, pp. 38-42.

Clarke, Peter, "Management accounting practices in large Irish manufacturing firms", IBAR, 18, 1997, pp. 136-152.

Cobb, I, Innes, John e Mitchell, Falconer, Activity based costing - problems in practice, CIMA, 1992.

Cooper, Robin, "Cost classification in unit-based and activity-based manufacturing cost systems", Journal of cost management, (Summer) 1990, pp. 4-14.

Cooper, Robin e Kaplan, Robert, Cost \& Effect, Using integrated cost systems to drive profitability and performance, Harvard Business School Press, 1998.

Cotton, William, Jackman, Susan e Brown, Richard, "Note on a New Zealand replication of the Innes et al. UK activity-based costing survey", Management Accounting Research, 14, $\mathrm{n}^{\circ} 1$ (Março), 2003, pp. 67-72.

Drury, Colin, "Standard costing: a technique at variance with modern management?", Management Accounting, 77(10), Nov. 1999, pp. 56-58.

Duarte, Paula, ABC - Estado actual de aplicação em Portugal, Dissertação do III Mestrado em Contabilidade e Auditoria, Universidade Aberta, 2002.

Glad, Ernest, "Implementation considerations for an ABC system", Management Accounting, 71, nº7 (Julho/Agosto), 1993, pp. 29-32.

Gomes, Conceição e Lúcia Rodrigues, "Apuramento das actividades económicas em que deve ser implementado o custeio baseado nas actividades", comunicação apresentada no XV Encontro Nacional da ADCES, Leiria, Maio 2003;

Hendricks, James, "Accounting for automation", Mechanical Engineering, 111(2), Fev. 1989, pp. 64-69.

Horngren, Charles, Foster, George e Datar, Srikant, Cost Accounting, a managerial emphasis, Prentice Hall, $10^{a}$ edição, 2000.

Innes, John, Mitchell, Falconer e Sinclair, Donald, "Activity-based costing in the UK's largest companies: a comparison of 1994 and 1999 survey results", Management Accounting Research, 11, n 3 (Setembro), 2000, pp. 349-362. 
Innes, John e Mitchell, Falconer, "A survey of activity-based costing in the UK's largest companies", Management Accounting Research, 6, n 2 (Junho), 1995, pp. 137-153.

Innes, John e Mitchell, Falconer, Activity based costing - A review with case studies, CIMA, 1989.

King, M., Lapsey, F., Mitchell, F., e Moyes, J., Activity Based Costing in Hospitals, A case study investigation, CMA publishing, 1994.

Maher, Michael, Stickney, Clyde e Weil, Ronald, Managerial Accounting an introduction to concepts, methods, and uses, Dryden Press, 1997.

Narayanan, V. e Sarkar, Ratna, The impact of activity based costing on managerial decision at insteel industries - a field study, Working paper, Harvard Business School, 1999.

http://www.crgroup.com/pdfs (20/2/2003)

Nicholls, Brent, "ABC in the UK - a status report", Management Accounting, 70, nº 5 (Maio), 1992, pp. 22-26.

Sandretto, Michael, "What kind of cost system do you need?", Harvard Business Review, Jan-Fev 1985, pp. 110-118.

Shim, Eunsup e Sudit, Ephraim, "How manufacturers price products", Management Accounting, Fevereiro 1995, pp. 37-39.

Vokurka, Robert e Lummus, Rhonda, "At what overhead levels does activitybased costing pay off?", Production \& Inventory Management Journal, $42, \mathrm{n}^{\circ} 1$ (Winter), 2001, pp. 40-49. 